\title{
Side Effects of Chloroquine and Hydroxychloroquine on Skeletal Muscle: a Narrative Review
}

\author{
Alzira Alves de Siqueira Carvalho ${ }^{1}$ (D) \\ Accepted: 29 September 2020 / Published online: 31 October 2020 \\ (C) Springer Nature Switzerland AG 2020
}

\begin{abstract}
Purpose of Review Concerning adverse neuromuscular effects, there are quite a few reports about the incidence and prevalence of chloroquine (CQ) and hydroxychloroquine (HCQ) myopathy. Given the above, I decided to explore the relationships of these drugs with skeletal muscle in an attempt to clarify how they affect the muscle now and in the future, as millions of people are using CQ and HCQ.

Recent Findings The literature review identified 28 publications about CQ/HCQ myopathy, totaling 56 patients, from 1963 to 2020. A compilation of all patients was carried out by computing demographic features, clinical aspects, laboratory exams, and clinical evolution. All articles but two represented a large series about incidence and prevalence of the myopathy. Fifty-nine percent used QC, mean daily dose was $393 \mathrm{mg}$ per day, and mean duration of treatment was 37 months. The predominant underlying diseases were rheumatoid arthritis $(42.8 \%)$ and lupus erythematosus $(26.8 \%)$. Respiratory distress was present in $12.5 \%$ in patients with proximal muscle weakness $(87.2 \%)$. Dysphagia and cervical and axial weakness were observed in a smaller percentage. Creatine kinase was elevated in 60.7\%, and EMG showed a myopathic pattern in 54\%. Muscle biopsy showed a vacuolar pattern in $53.7 \%$, and curvilinear bodies (CB) were the predominant ultrastructural finding (86.8\%). After drug withdrawal, $85.4 \%$ of patients improved, and $12.7 \%$ died from other causes than myopathy.

Summary CQ and HCQ myopathy has been known for a long time, but the incidence is low, being described only with long-term use. The use of these drugs for a short period has not been reported, although a prolonged elimination half-life of these drugs actually exists.
\end{abstract}

Keywords Chloroquine $\cdot$ Hydroxychloroquine $\cdot$ Myopathy $\cdot$ Myotoxicity

\section{Introduction}

The world faces the deadly COVID-19 pandemic, the most challenging situation in a century that we have confronted. Currently, emerging therapies and repurposing of old drugs have been considered therapeutic strategies, including chloroquine (CQ) and hydroxychloroquine (HCQ) [1, 2], both drugs showing activity against COVID-19 in vitro [3]; however, the level of preclinical and clinical data is not strong and must be approved by a higher level of evidence $[4,5]$.

This article is part of the Topical Collection on Clinical Pharmacology

Alzira Alves de Siqueira Carvalho neurogenetica@fmabc.br

1 Department of Neurosciences - Neuromuscular Service, Centro Universitário Saúde ABC, Av. Lauro Gomes, 2000 - Vila Sacadura Cabral, Santo André, São Paulo 09060-870, Brazil
Specifically, at the beginning of 1943, the incidental repurposing of antimalarial drugs (quinacrine and CQ) was demonstrated after a crucial improvement of cutaneous rashes and arthritis in soldiers on malaria prophylaxis. Sometime later, in 1951, the first trial showed the efficacy of mepacrine in lupus erythematosus from 18 cases. However, nine of the results were very dramatic, and the other nine showed goodto-slight improvement [6].

CQ and HCQ are disease-modifying anti-rheumatic drugs (DMARDs) that suppress the clinical progression of several autoimmune diseases (e.g., systemic lupus erythematosus, rheumatoid arthritis, antiphospholipid syndrome, primary Sjögren's syndrome, and sarcoidosis) [7].

Over the past few decades, these two compounds have also drawn attention as potential antiviral agents [8].

The suggested mechanism of action is raising the $\mathrm{pH}$ of the cell membrane, thus making it difficult for the virus to enter cells and interfering in the final stages of virus replication [3]. Also, they have an immunomodulatory effect and block the 
cascade of events that lead to acute respiratory distress syndrome [9]. Regardless of promising experimental studies, clinical trials have shown controversial effects $[10,11]$.

Peripheral nervous system manifestations caused by COVID19 are rare, with the most common ones being hypogeusia (5.6\%) and hyposmia (5.1\%), while skeletal muscle complaints were reported in $10.3 \%$ of patients; however, electromyography, muscle MRI, or histopathologic findings were not mentioned [12]. Two recently published studies of COVID-19 in China reported myalgia or fatigue in $44-70 \%$ of hospitalized patients and increased creatine kinase(CK) in up to $33 \%$ of admitted patients $[13,14]$. Additionally, a third of patients infected with other coronavirus infections manifested with myalgias and elevated CKs [15] and rhabdomyolysis [16]. So, it is possible that coronavirus infections may cause a viral myositis [17].

Although the good tolerability of CQ and HCQ is wellproven and considered safe even during pregnancy [18], they can cause side effects, some of which are classified as "nonserious" and do not impede the continuation of treatment. In contrast, others are considered "serious" and require drug suspension, which, unfortunately, does not always lead to their complete resolution. The first group is represented by gastrointestinal and cutaneous manifestations, while retinal, neuromuscular, and cardiac toxicities are part of the second group [19].

Concerning adverse neuromuscular effects, there are quite a few reports about the incidence and prevalence of CQ and HCQ myopathy. Given the above, I decided to explore the relationships of these drugs with skeletal muscle in an attempt to clarify how they affect the muscle now and in the future, as millions of people are using CQ and HCQ.

The review of the literature using PubMed let me identify 28 publications about antimalarial myopathy (only case reports or case series), totaling 56 patients, from 1963 to April 2020 [20-41]. A compilation of data from these studies was carried out and analyzed in a general context by computing demographic features (age, gender, previous diagnosis, duration of $\mathrm{CQ} / \mathrm{HCQ}$ treatment), clinical aspects (muscle weakness, respiratory distress), laboratory tests (creatine kinase (CK) levels, morphological and ultrastructural findings from skeletal muscle biopsy, electromyography), and clinical evolution (improvement or death). Mean and median values were obtained for age, daily dose, treatment duration, and CK values, and percentage values in relation to gender, underlying disease, the drug used, clinical symptoms, CK elevation rates, respiratory distress, EMG features, muscle biopsy findings, and evolution were also analyzed.

\section{Results}

Two articles presented large studies of the incidence and prevalence of antimalarial myopathy, the others being case reports. These findings are detailed in Table 1 and Table 2.
A previous and elegant study [26] selected 214 patients from a retrospective review of 4405 patients who initiated antimalarial therapy from January 1987 to April 1993 due to different rheumatic disorders. From these, only three patients presented with CQ myopathy from a total of 303 patient-years with an estimated incidence of 1 in 100 patient-years [26]. After 10 years, the second series of patients was published as a prospective study, which evaluated over 3 years all patients with rheumatic diseases who were taking antimalarial drugs. A total of 119 patients were included, 15 being detected with CQ or HCQ myopathy. The annual incidence was $1.2 \%$, with a prevalence of $6.7 \%$ [31].

The mean age of affected patients was 59 years (median 59, varying from 28 to 89 years), with a clear predominance of females $(73.2 \%)$. The preference for the use of CQ or HCQ was not explained in those previous reports: $58.9 \%$ used CQ and $41 \%$ used HCQ. The median daily dose was $400 \mathrm{mg}$ per day (mean $393 \mathrm{mg}$ ), and the mean duration of treatment was 37 months (median 24 months). The underlying diseases treated with these drugs were rheumatoid arthritis, $42.8 \%$; systemic and discoid lupus erythematosus (SLE/DLE), 26.8\%; other rheumatic disorders (progressive systemic sclerosis (PSS), connective tissue disorder, psoriatic arthritis, polymyositis/ calcinosis/Raynaud's phenomenon, esophageal dysmotility/ sclerodactyly/telangiectasia, Sjögren's syndrome/primary biliary cirrhosis, PSS/ interstitial lung disorder), 17.8\%; and a miscellaneous group (chronic graft-versus-host disease, shoulder pain, lumbar spondylosis, knee arthritis, morphea, polymyalgia rheumatica), $12.6 \%$ (Table 1).

Respiratory distress was present in $12.5 \%$ of patients as an initial symptom and associated with proximal muscle weakness (87.2\%). Dysphagia, cervical weakness, and axial weakness were also observed in smaller percentages: $8.9 \%, 17.8 \%$, and $1.8 \%$, respectively.

In laboratory tests, 34 (60.7\%) patients underwent measurement of CK level that was elevated in $60.7 \%$ (mean value, $339.5 \mathrm{IU}$; median value, $613 \mathrm{IU}$; ref. value $<130$ to $170 \mathrm{IU}$ ). EMG was performed for 50 patients with a predominance of a myopathic pattern (54\%), followed by a neuromyopathic pattern in $16 \%$ and neurogenic in only one (2\%).

Muscle biopsy, analyzed by optical microscopy (OM), was performed in 54 (96.4\%) patients showing a vacuolar pattern in $53.7 \%$ and non-specific findings in $46.2 \%$ (Fig. 1). A total of $38(67.8 \%)$ muscle samples were processed for electron microscopy (EM); the predominant ultrastructural finding was the presence of $\mathrm{CB}$ in $38(86.8 \%)$ patients, while myeloid bodies and non-specific findings were present only in three cases $(8.0 \%)$. From 16 patients with a non-specific finding by OM, 15 (93.7\%) demonstrated the presence of $\mathrm{CB}$ and myeloid bodies on ultrastructural examination. After withdrawing the drug (CQ or HCQ), $85.4 \%$ showed an improvement, and $12.7 \% \%$ died (Table 2 and Table 3). 


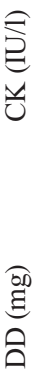

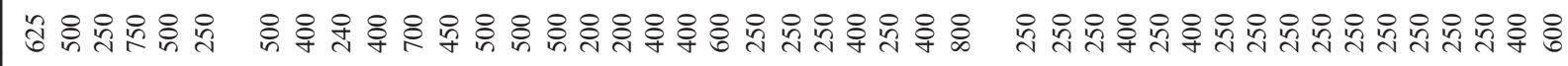

d =

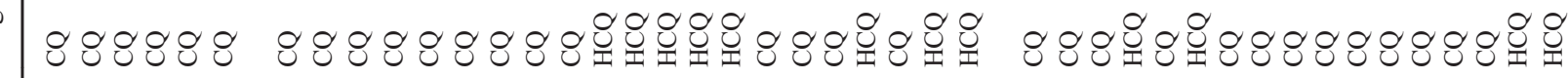

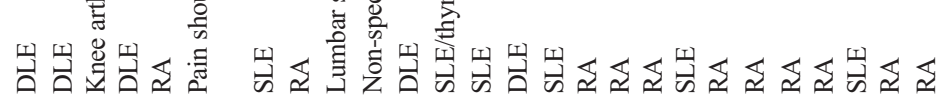

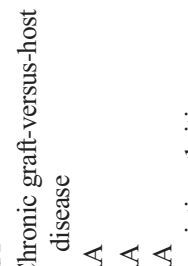

兽

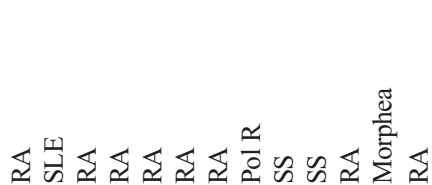

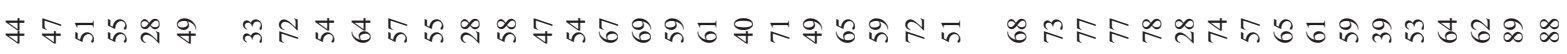

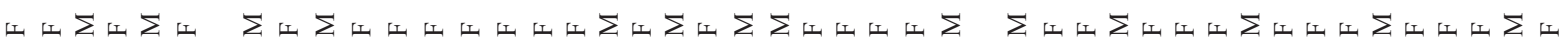

-

产

$\overline{\bar{\sigma}}$ 


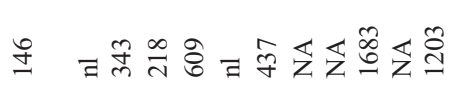

焉

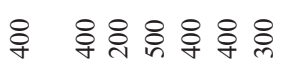

\&

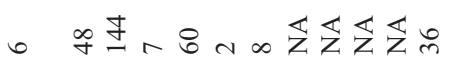

舀

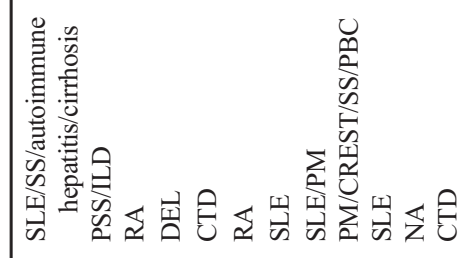

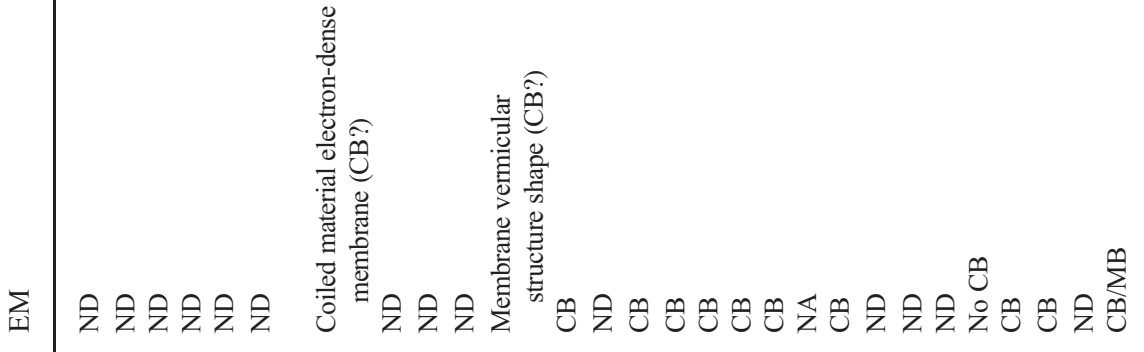

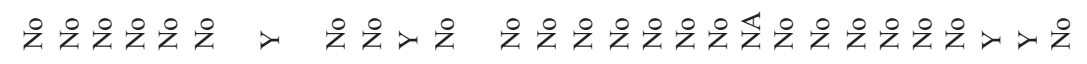

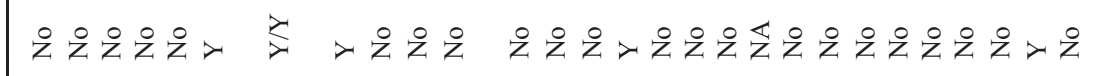

疍

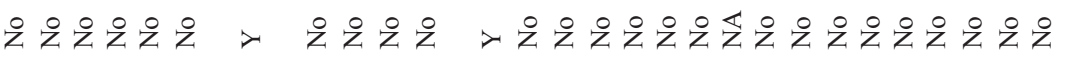

空

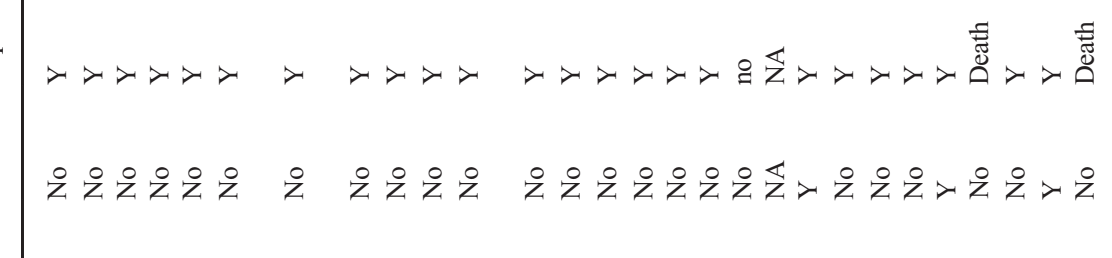

西

妾

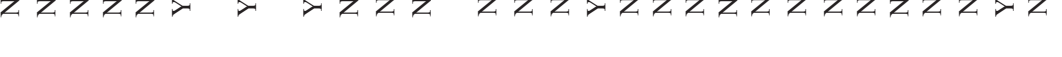

更

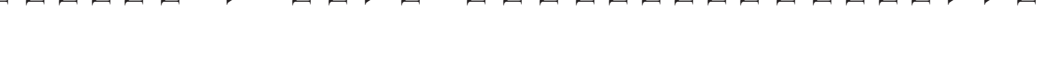

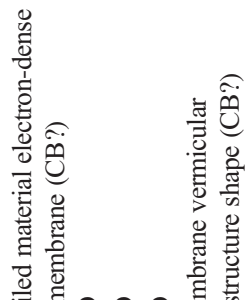

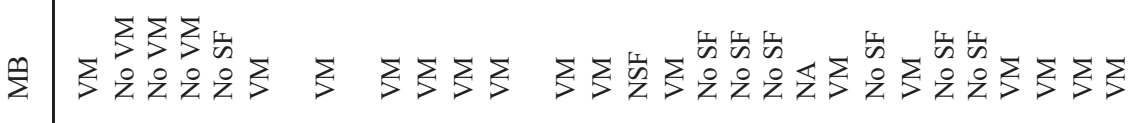

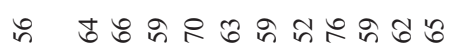

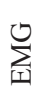

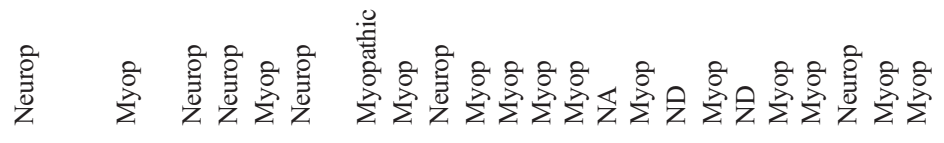

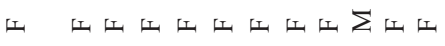

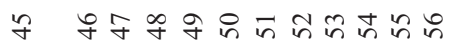

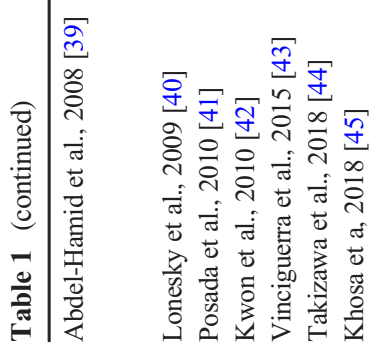

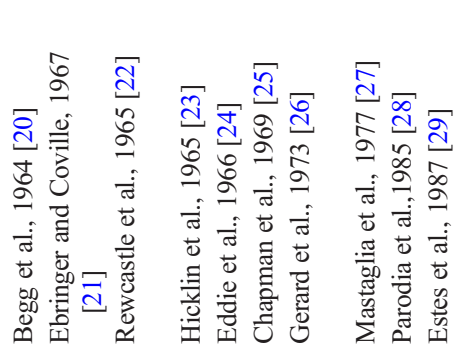

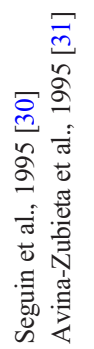

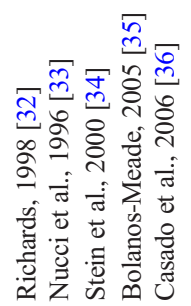




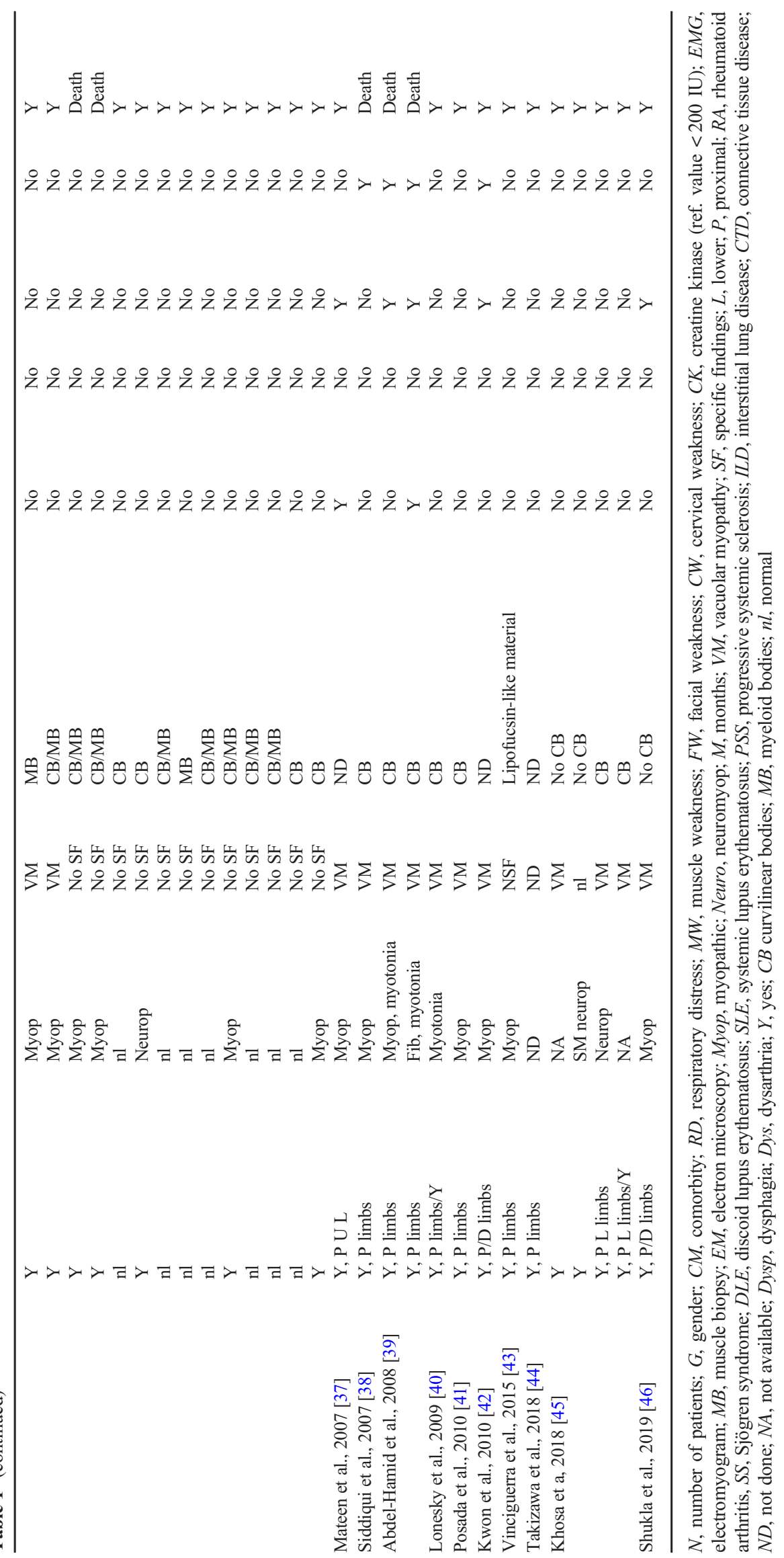


Table 2 Data compilation of CQ and HCQ myopathy based in the literature review from 1963 to April/2020

\begin{tabular}{|c|c|c|}
\hline Data & Values & $n$ \\
\hline \multirow[t]{3}{*}{ Age (year) } & $59(\mathrm{M})$ & 56 \\
\hline & 59 (Med) & \\
\hline & $28-89$ & \\
\hline $\mathrm{G}(\mathrm{F}) \%$ & 73.2 & 56 \\
\hline \multicolumn{3}{|l|}{ Underlying disease (\%) } \\
\hline RA & 42.8 & 56 \\
\hline SLE & 26.8 & \\
\hline ORD & 17.8 & \\
\hline Misc & 12.6 & \\
\hline \multicolumn{3}{|l|}{ Drug \% } \\
\hline CQ & 58.9 & 56 \\
\hline HQC & 41 & \\
\hline $\mathrm{DD}(\mathrm{mg} / \mathrm{d})$ & 393(M) & 56 \\
\hline & 400(Med) & \\
\hline $\mathrm{DT}(\mathrm{m})$ & $37(\mathrm{QC})$ & 56 \\
\hline & 24(HCQ) & \\
\hline PW/CW/Dys (\%) & $87.2 / 17.8 / 8.9$ & 56 \\
\hline Elevated CK \%/M/Med & $60.7 / 613 / 339$ & 34 \\
\hline $\mathrm{RD} \%$ & 12.5 & 56 \\
\hline \multicolumn{3}{|l|}{ EMG \% } \\
\hline Myop & 54 & 50 \\
\hline Neuromyo & 16 & \\
\hline $\mathrm{N}$ & 2 & \\
\hline \multicolumn{3}{|l|}{ Muscle biopsy $\%$} \\
\hline Vacuolar & 53.7 & 54 \\
\hline NSF & 46.2 & \\
\hline \multicolumn{3}{|l|}{$\mathrm{MB}(\mathrm{EM}) \%$} \\
\hline $\mathrm{CB}$ & 86.8 & 38 \\
\hline MB & 8 & \\
\hline Impr/death (\%) & $85.4 / 12.7$ & 55 \\
\hline
\end{tabular}

$M$, mean; $M e d$, median; $y$, year; $G$, gender; $F$, female; $C Q$, chloroquine; $H C Q$, hydroxychloroquine; $D D$, daily dose; $D T$, duration treatment; $m$, months; $P W$, proximal weakness; $C W$, cervical weakness; $D y s$, dysphagia; $O M$, optic microscopy; $E M$, electron microscopy; $R A$, rheumatoid arthritis; $S L E$, systemic lupus erythematosus; $O R D$, other rheumatic diseases; Misc, miscellaneous; $C Q$, chloroquine; $H Q C O R D$, other rheumatic disorders; $C K$, creatine kinase; $R D$, respiratory distress; $M y o p$, myopathic; Neuromyo, neuromyopathic; $N$, neuropathy; $N S F$, no specific findings; $C B$, curvilinear bodies; $M B$, myeloid bodies; Impr, improvement

\section{Discussion}

The muscle toxicity of CQ and HCQ is often unrecognized and is likely to be more common than described in the literature since the diagnosis of muscle toxicity attributable to these drugs is quite challenging. This is mainly because the underlying diseases and associated medications mask the symptoms of possible harmful effects on skeletal, cardiac, and smooth muscle, and also because of a lack of classic symptoms and/or morphological abnormalities of muscle. CQ has a large volume of distribution in the human body with an elimination half-life of 20-60 days and a tendency to accumulate in metabolically active tissues like the brain, muscle, skin, heart, and liver than in blood $[9,13]$. Based on that, the recommended dose of $500 \mathrm{mg}$ twice per day can approach dangerous thresholds with prolonged treatment compared with a lethal dose of chloroquine $(5 \mathrm{~g})$ in adults.

The pathways of antimalarial drugs involved in muscle toxicity, besides being complex, are far from being fully explained, and available data are scanty with no long-term monitoring of experimental models or detailed molecular analysis. Even now, it is difficult to relate the composite action mechanisms of these drugs to their efficacy in different autoimmune and infectious disorders.

HCQ and CQ belong to a class of drugs known as 4aminoquinolines (containing an amino group attached to a quinoline ring). They are most notable for their roles as antimalarial drugs $[9,13]$. Both drugs have a flat aromatic core structure. They are classified as weak bases due to the presence of a basic side chain, which contributes to the accumulation of these drugs in intracellular compartments, especially lysosomal organelles. Their amphiphilic properties elevate intralysosomal $\mathrm{pH}$ causing specific lysosomal disarrangement and autophagic dysfunctions, which result in vacuolar changes in muscle. They also specifically inhibit the lysosomal proteinase, cathepsin B, responsible for intracellular proteolysis [42].

The rimmed vacuolar changes found in muscle have been considered the most representative aspect in muscle biopsies of patients with myopathy induced by antimalarials; however, the absence of these vacuoles in some cases does not exclude the diagnosis [25]. This study demonstrated by OM the absence of vacuoles in half the sample $(53.7 \%)$, which could be partially explained by the interval between the interruption of therapy and timing of the muscle biopsy beyond the technical difficulties in interpreting the biopsies. On the other side, their presence has also been described in other neuromuscular disorders, such as sporadic and familial inclusion body myositis, myofibrillary myopathy, oculopharyngeal muscular dystrophy, and some other myopathies [43-46].

Considering the high percentage of CB (86.8\%) found on ultrastructural exam makes us think that EM is more sensitive for the diagnosis of CQ or HCQ induced myopathy than OM. Also, two previous reports $[17,21]$ observed the presence of coiled- and vermicular-shaped material very similar to $\mathrm{CB}$ on EM. So, considering both cases, the percentage of $\mathrm{CB}$ would increase to $92 \%$ of cases. By contrast, the literature described $\mathrm{CB}$ as a rare finding on muscle tissue seen in some but not all patients who have received treatment with antimalarials [29, 37]. $\mathrm{CB}$ has been described for the first time in different tissues, including muscle, of patients with late infantile and juvenile forms of Batten disease. They appear as tightly packed, short, curved linear bodies under an electron microscope [47-50]. 

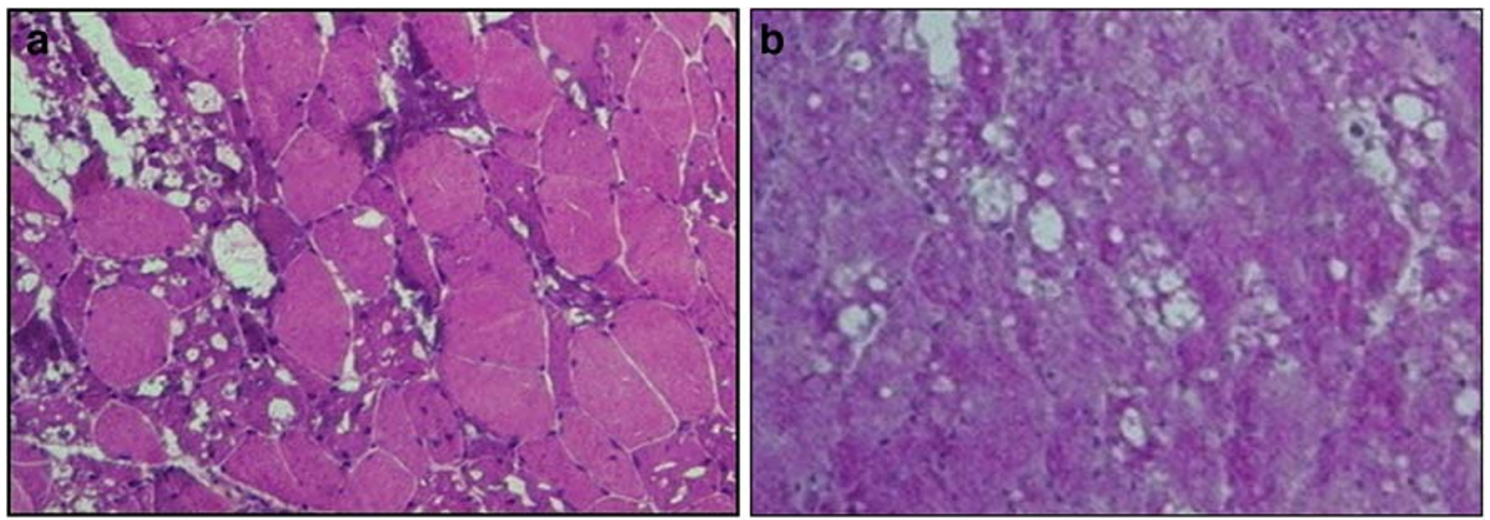

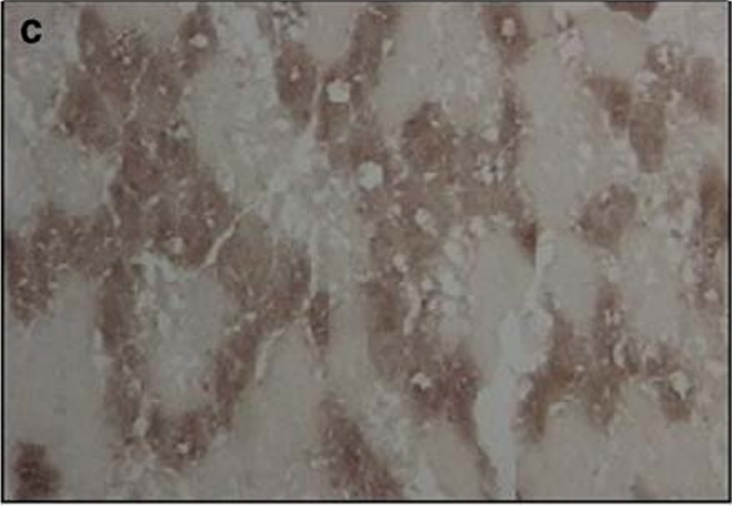

Fig. 1 Muscle biopsy findings from patient with dermatomyositis after chloroquine use for 6 months. a H\&E: fiber-size variation and multiple intracytoplasmic vacuoles. b PAS: vacuoles without glycogen. c ATPase

Another relevant aspect is that the consequences of using CQ and HCQ are not restricted to the peripheral organelles of the cell and seem to involve other pathways. Nrf2 is a basic leucine zipper (bZIP) protein that regulates the expression of antioxidant proteins that protect against oxidative damage triggered by injury and inflammation [51]. In vacuolar muscle disorders, such as autophagic vacuolar myopathy induced by $\mathrm{CQ} / \mathrm{HCQ}$, Nrf2 is persistently activated with negative consequences on organ functions. The chronic activation of Nrf2 in skeletal muscle results in changes in cellular redox potential, a response that contributes to muscle pathologies [52-54].

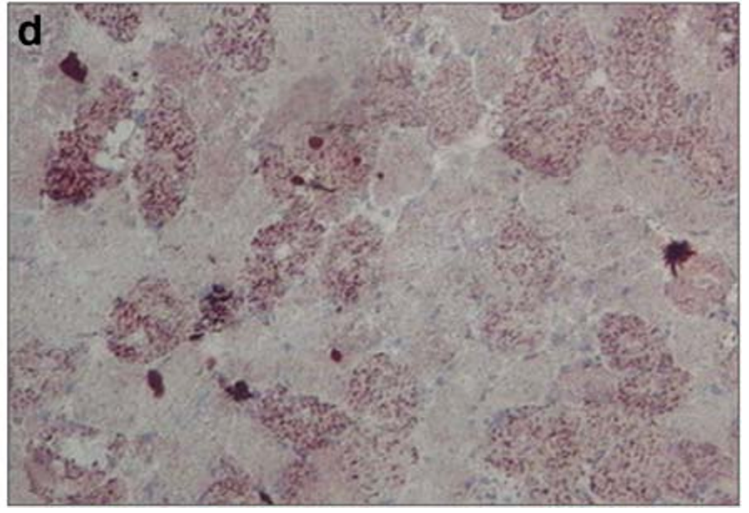

4.35: presence of vacuoles in type 1 and 2 fibers. $\mathbf{d}$ Oil Red O: vacuoles without lipides (personal archive from author)

Looking at some of the results, I was initially surprised not to find seemingly typical clinical symptoms and biopsy changes in this compilation. A study conducted by Casado and colleagues suggested serial muscle enzyme screening of patients on these therapies as a way to identify patients at risk. All 15 patients with myopathy presented increased levels, mild to moderate, of CK or lactic dehydrogenase. By contrast, Kalajian and Callen [55] did not find an association between elevated serum muscle enzymes and underlying antimalarial-induced myopathy in patients taking CQ or HCQ.

Table 3 Data from patients that evolved with death

\begin{tabular}{cllllllll}
\hline Patient & Gender & Age & Underlying disease & Drug & Dur treat $(\mathrm{M})$ & DD $(\mathrm{mg} / \mathrm{d})$ & RD & Cause of death \\
\hline 25 & F & 59 & RA & CQ & 10 & 250 & No & Cardiac insufficiency and broncopneumonia \\
29 & M & 68 & RA & CQ & 31 & 250 & No & Myocardial infarction \\
31 & M & 77 & Psoriatic arthritis & HQC & 74 & 400 & No & Sepsis \\
32 & F & 78 & RA & CQ & 28 & 250 & No & Heart failure \\
44 & F & 88 & RA & HQC & 60 & 600 & Y & Obstructive airway disease \\
45 & F & 56 & SLE/SS/autoimmune hepatitis & HQC & 6 & 400 & Y & Gallstones and sepsis \\
46 & F & 64 & PSS/ILD & HQC & 48 & 400 & Y & Pulmonary fibrosis/Nocardia/Aspergillus \\
\hline
\end{tabular}

$C Q$, chloroquine; $H Q C$, hydroxichloroquine; Dur treat $(M)$, duration of treatment; $D D$, daily dose; $R D$, respiratory distress; $M$, months; $m / d$, milligrams per day; $Y$, yes 
In this review, seven asymptomatic patients with mildly elevated muscle enzymes (CK or DHL) and normal EMG presented curvilinear and myeloid bodies on EM as a unique finding. The isolated presence of this specific ultrastructural finding in skeletal muscle may not always signify a muscle disorder. However, it could be a muscular accumulation of CQ/HCQ or their metabolites, as demonstrated by Kumamoto et al., who observed dense membranous structures $(\mathrm{CB})$ in soleus muscle fibers by EM in CQtreated rats $[31,56]$.

Experimental studies have suggested that the absolute tissue levels of CQ are 2.5 times higher than those of HCQ. Thus, the depositing of the drug in several tissues with subsequent enzyme inactivation, which is the proposed mechanism for toxicity, might be more likely to occur with CQ [26]. Nevertheless, we did not observe crucial differences between compounds in terms of symptoms, morphological analyses, or clinical evolution. The number of patients using CQ or HCQ, $58.9 \%$ and $41 \%$, respectively, was not very different; specifically, in relation to morphological findings, we identified almost the same number of cases with vacuolar myopathy in the group using CQ [15] and HCQ [17].

Concerning outcomes, prompt recovery was usual. Improvement after discontinuation of therapy occurred in $85.4 \%$ of cases, and seven deaths $(12.7 \%)$ were reported. Apparently, five of the deaths were not related to the antimalarial drug (dose, treatment duration), but as a result of underlying disease complications, and the other two deaths occurred due to cardiac complications. Despite major drug interactions of CQ and HCQ with other medications leading to a greater risk of arrhythmia, there were no reports of this as being as the cause of death (Table 3).

\section{Conclusions}

CQ and HCQ myopathy has been known for a long time, but the reports are sporadic, and the incidence is low, being described only with long-term use. The use of these drugs even for a short period requires attention as a prolonged elimination half-life of these drugs can be harmful.

Data Availability Statement We declare that the supplementary material is available as a supplementary table.

\section{Compliance with Ethical Standards}

Conflict of Interest The author declares no conflicts of interest.

Human and Animal Rights and Informed Consent This article does not contain any studies with human or animal subjects performed by any of the authors.
Ethical Publication Statement We confirm that we have read the Journal's position on issues involved in ethical publication and affirm that this report is consistent with those guidelines and according to the Declaration of Helsinki.

\section{References}

1. Barlow A, Landolf KM, Barlow B, et al. Review of emerging pharmacotherapy for the treatment of coronavirus disease. Pharmacotherapy. 2020. https://doi.org/10.1002/phar.2398.

2. Singh AK, Singh A, Shaikh A, Singh R, Misra A. Chloroquine and hydroxychloroquine in the treatment of COVID-19 with or without diabetes: A systematic search and a narrative review with a special reference to India and other developing countries. Diabetes Metab Syndr. 2020;14(3):241-6.

3. Yao X, Ye F, Zhang M, Cui C, Huang B, Niu P. In vitro antiviral activity and projection of optimized dosing design of hydroxychloroquine for the treatment of severe acute respiratory syndrome coronavirus 2 (SARS-CoV-2). Clin Infect Dis ciaa237. 2020. https://doi.org/10.1093/cid/ciaa237.

4. Shukla AM, Archibald LK, Wagle Shukla A, Mehta HJ, Cherabuddi K. Chloroquine and hydroxychloroquine in the context of COVID-19. Drugs Context. 2020;9:2020-4-5. https://doi.org/10. 7573/dic.2020-4-5.

5. Geleris J, Sun Y, Platt J, et al. Observational study of Hydroxychloroquine in hospitalized patients with Covid-19. N Eng1 J Med. 2020;382(25):2411-8. https://doi.org/10.1056/ NEJMoa2012410.

6. Ben-Zvi I, Kivity S, Langevitz P, Shoenfeld Y. Hydroxychloroquine: from malaria to autoimmunity. Clin Rev Allergy Immunol. 2012;42(2):145-53. https://doi.org/10.1007/ s12016-010-8243-x.

7. Taherian E, Rao A, Malemud C, Askari A. The biological and clinical activity of anti-malarial drugs in autoimmune disorders. Curr Rheumatol Rev. 2013;9:45-62.

8. Savarino A, Boelaert JR, Cassone A, Majori G, Cauda R. Effects of chloroquine on viral infections: na old drug against today's diseases. Lancet Infection Diseases. 2003;3(11):722-7.

9. Schrezenmeier E, Dorner T. Mechanisms of action of hydroxychloroquine and chloroquine: implications for rheumatology. Nat Rev Rheumatol. 2020;16:155-66.

10. Gautret P, Lagier JC, Parola P, et al. Hydroxychloroquine and azithromycin as a treatment of COVID-19: results of an open-label nonrandomized clinical trial. Int J Antimicrob Agents. 2020. https:// doi.org/10.1016/j.ijantimicag.2020.105949.

11. Molina JM, Delaugerre C, Le Goff J, et al. No evidence of rapid antiviral clearance or clinical benefit with the combination of hydroxychloroquine and azithromycin in patients with severe COVID-19 infection. Med Mal Infect. 2020;50(4):384. https://doi. org/10.1016/j.medmal.2020.03.006.

12. Mao L, Jin H, Wang M, et al. Neurologic manifestations of hospitalized patients with coronavirus disease 2019 in Wuhan, China. JAMA Neurol. 2020:e201127. https://doi.org/10.1001/ jamaneurol.2020.1127.

13. Huang C, Wang Y, Li X, et al. Clinical features of patients infected with 2019 novel coronavirus in Wuhan, China. Lancet. 2020;395(10223):497-506.

14. Wang D, Hu B, Hu C, et al. Clinical characteristics of 138 hospitalized patients with 2019 novel coronavirus- infected pneumonia in Wuhan, China. JAMA Epub. 2020 Feb 7. https://doi.org/10. 1001/jama.2020.1585.

15. Tsai LK, Hsieh ST, Chao CC, et al. Neuromuscular disorders in severe acute respiratory syndrome. Arch Neurol. 2004;61(11): 1669-73. https://doi.org/10.1001/archneur.61.11.1669. 
16. Chen LL, Hsu CW, Tian YC, Fang JT. Rhabdomyolysis associated with acute renal failure in patients with severe acute respiratory syndrome. Int J Clin Pract. 2005;59(10):1162-6. https://doi.org/ 10.1111/j.1368-5031.2005.00540.x.

17. Guidon AC, Amato AA. COVID-19 and neuromuscular disorders. Neurology. 2020;94(22):959-69. https://doi.org/10.1212/WNL. 0000000000009566.

18. Divala TH, Mungwira RG, Mawindo PM, et al. Chloroquine as weekly chemoprophylaxis or intermittent treatment to prevent malaria in pregnancy in Malawi: a randomized controlled trial. Lancet Infect Dis. 2018;18(10):1097-107.

19. Plantone D, Koudriavtseva T. Current and future use of Chloroquine and Hydroxychloroquine in infectious, immune, neoplastic, and neurological diseases: A mini-review. Clin Drug Investig. 2018;38(8):653-71. https://doi.org/10.1007/s40261-0180656-y.

20. Whisnant JP, Espinosa RE, Kierland RR, et al. Chloroquine neuromyopathy. Mayo Clin Proc. 1963;38:1-13.

21. Begg TB, Simpson JA. Chloroquine neuromyopathy. Brit med J. 1964;1:770.

22. Ebringer A, Colville P. Chloroquine Neuromyopathy associated with Keratopathy and retinopathy. Brit Med J. 1967;2:219-20.

23. Rewcastle NB, Humphrey JG. Vacuolar myopathy: clinical, histochemical and microscopic study. Arch Neurol. 1965;12:570-82.

24. Hicklin JA. Chloroquine neuromyopathy. Ann phys Med. 1968;9: 189-92.

25. Eddie J, Ferrier M. Chloroquine myopathy. J Neurol Neurosurg Psychiatry. 1966;29:331-7.

26. Chapman S, Ewen W. Chloroquine-induced myopathy. Br J Dermatol. 1969;81:217-9.

27. Gerard JM, Stoupel N, A Colher et AL. Morphologlc study of a neuromyopathy caused by prolonged chloroqume treatment. Eur Neurol. 1973;9:363-79.

28. Mastaglia FL, Papadimitriou JM, Dawkins RL et AL. Vacuolar myopathy associated with chloroquine, lupus erythematosus and thymoma. J Neurol Sci. 1977;34:315-28.

29. Parodia A, Regestab G, Reboraa A. Chloroquine-induced Neuromyopathy. Dermatologica. 1985;171:203-5.

30. Estes ML, Ewing-Wilson D, Chou SM, et al. Chloroquine neuromyotoxicity. Clinical and pathologic perspective. Am J Med. 1987;82:447-55.

31. Seguin P, Camus C, Leroy JP, et al. Respiratory failure associated with hydroxychloroquine neuromyopathy [letter]. Eur Neurol. 1995;35:236-7.

32. Avina-Zubieta JA, Johnson ES, Suarez-Almazor ME, et al. Incidence of myopathy in patients treated with antimalarials. A report of three cases and a review of the literature. $\mathrm{Br} \mathrm{J}$ Rheumatol. 1995;34:166-70.

33. Richards AJ. Hydroxychloroquine myopathy. J Rheumatol. 1998;25:1642-3.

34. Nucci A, Queiroz LS, Samara AM. Chloroquine neuromyopathy. Clin Neuropathol. 1996;15(5):256-8.

35. Stein M, Bell MJ, Ang LC. Hydroxychloroquine neuromyotoxicity. J Rheumatol. 2000;27:2927-31.

36. Bolaños-Meade J, Zhou L, Hoke A, et al. Hydroxychloroquine causes severe vacuolar myopathy in a patient with chronic graftversus-host disease. Am J Hematol. 2005;78(4):306-9.

37. Casado E, Gratacos J, Tolosa C, et al. Antimalarial myopathy: an underdiagnosed complication? Prospective longitudinal study of 119 patients. Ann Rheum Dis. 2006;65:385-90.
38. Mateen J, Keegan M. Severe, reversible dysphagia from chloroquine and hydroxychloroquine myopathy. Can J Neurol Sci. 2007;34:377-9.

39. Siddiqui K, Huberfeld I, Weidenheim M, et al, Hydroxychloroquine-induced toxic myopathy causing respiratory failure. Chest. 2007;131:588-90.

40. Abdel-Hamid H, Oddis CV, Lacomis D. Severe hydroxychloroquine myopathy. Muscle Nerve. 2008;38(3): 1206-10.

40. Lonesky TA, Kreuter JD, Wortmann RL, et al. Hydroxychloroquine and colchicine induced myopathy. J Rheumatol. 2009;36(11): 2617-8.

42. Posada C, García-Cruz A, García-Doval I, et al. Chloroquine-induced myopathy. Lupus. 2011;20(7):773-4.

43. Kwon JB, Kleiner A, Ishida K, et al. Hydroxychloroquine-induced myopathy. J Clin Rheumatol. 2010;16:28-31.

44. Vinciguerra C, Sicurelli F, Fioravanti A, et al. Hydroxychloroquine neuromyotoxicity: a case with rapid course and complete recovery. Neurol Sci. 2015;36:2293-4.

45. Takizawa N, Fujita Y. A rare but reversible cause of myopathy: Hydroxychloroquine induced myopathy. Arc Cas Rep C Med. 2018;3(3):158.

46. Khosa S, Khanlou N, Khosa S, et al. Hydroxychloroquine- induced autophagic vacuolar myopathy with mitochondrial abnormalities. Neuropathol. 2018;38:646-52.

47. Shukla S, Gultekin SH, Saporta M. Pearls \& Oy-sters: Hydroxychloroquine-induced toxic myopathy mimics Pompe disease: critical role of genetic test. Neurology. 2019;92(7):e742-5.

48. Stauber WT, Hedge AM, Trout JT, et al. Inhibition of lysosomal function in red and white skeletal muscles by chloroquine. Exp Neurol. 1981;71:295-306.

49. Dubowitz V, Sewry CA. Oldfors A. Fourth ed. Philadelphia: Saunders Elsevier Press; 2013. p. 592.

50. Neville E, Maunder-Sewry A, McDougall J, Sewell JR, et al. Chloroquine-induced cytosomes with curvilinear profiles in muscle. Muscle Nerve. 1979;2(5):376-81. https://doi.org/10.1002/mus. 880020509 .

51. Tebay LE, Robertson H, Durant ST, et al. Mechanisms of activation of the transcription factor Nrf2 by redox stressors, nutrient cues and energy status, and pathways through which it attenuates degenerative disease. Free Radic Biol Med. 2015;88:108.

52. Khelfi A, Azzouzc M, Abtrouna R, et al. Direct mechanism of action in toxic myopathies. Ann Pharm Fr. 2017;75(5):323-43.

53. Duleh S, Wang X, Komirenko A, et al. Activation of the Keap1/ Nrf2 stress response pathway in autophagic vacuolar myopathies. Acta Neuropathol Commun. 2016;31;4(1):115.

54. Bellezzaa I, Giambancoa I, Minellia A, et al. Nrf2-Keap1 signaling in oxidative and reductive stress. (review). BBA - Molecular Cell Research. 2018;1865:721-33.

55. Kalajian AH, Callen JP. Myopathy induced by antimalarial agents: the relevance of screening muscle enzyme levels. Arch Dermatol. 2009; 145:597-600.

56. Kumamoto T, Araki S, Watanabe S, Ikebe N, Fukuhara N. Experimental chloroquine myopathy: morphological and biochemical studies. Eur Neurol. 1989;29(4):202-7. https://doi.org/10. $1159 / 000116412$

Publisher's Note Springer Nature remains neutral with regard to jurisdictional claims in published maps and institutional affiliations. 